\title{
Endonasal Endoscopic Transsphenoidal Chiasmapexy With Silicone Plates for Empty Sella Syndrome
}

\author{
-Technical Note-
}

\author{
Shigeki KUBO, Hiroshi HaSEGAwA, Toshihiko INUI*, Shinsuke TOMINAGA*, \\ and Toshiki YOSHIMINE**
}

\begin{abstract}
Endoscopic Neurosurgery Center and ${ }^{*}$ Department of Neurosurgery, Tominaga Hospital, Osaka; ** Department of Neurosurgery, Osaka University Graduate School of Medicine, Osaka
\end{abstract}

\begin{abstract}
Silicone plates sutured together to form blocks were used for extradural elevation of the sella floor in two patients who underwent chiasmapexy for visual disturbance associated with empty sella syndrome. A 36-year-old woman had been treated for prolactinoma for about 19 years with bromocriptine and then presented with left visual disturbance. A 79-year-old man presented with right blurred vision of unknown cause other than empty sella. The sella turcica was accessed via the endonasal transsphenoidal approach under endoscopic guidance. The bony sellar floor was opened with a drill. Two or three pieces of 1-mm-thick silicone plate were sutured to make a block. Two or three blocks were inserted into the epidural space to elevate the sellar contents. Visual symptoms improved in both patients. Silicone is biocompatible and not absorbable. Silicone plates are elastic and easy to handle during insertion, but firm enough to support the sella. The elevation can be adjusted by changing the number of plates in the block. The endonasal endoscopic approach is minimally invasive and particularly suitable for transsphenoidal extradural chiasmapexy for empty sella syndrome.
\end{abstract}

Key words: chiasmapexy, empty sella syndrome, endoscopy, sella turcica, silicone, transsphenoidal approach

\section{Introduction}

Primary empty sella, or empty sella of unknown cause, is found in approximately $5 \%$ of the population, and is asymptomatic in most cases. ${ }^{6,7)}$ Secondary empty sella usually develops following radiation therapy or surgery to the pituitary gland or during bromocriptine treatment for prolactinproducing adenoma. ${ }^{5,8,10)}$ Symptoms associated with the empty sella are referred to as empty sella syndrome, and include headache, visual disturbance, cerebrospinal fluid rhinorrhea, and pituitary hormone dysfunction. ${ }^{5,6)}$ Visual disturbance is caused by traction of the chiasm or the optic nerves toward the sellar floor by the adhesion scar or pituitary stalk, for which chiasmapexy is usually indicated..$^{3,7,14)}$

Chiasmapexy is preferably performed via the transsphenoidal rather than the transcranial approach. ${ }^{7,8,15)}$ During chiasmapexy, traction on the

Received July 9, 2004; Accepted January 25, 2005 optic system is relieved by elevating the sellar floor extradurally with various materials, the most common being autologous tissues, including fat, muscle, fascia, bone, and cartilage. ${ }^{7,8,14,15)}$ Fat and muscle may be absorbed over the long term after surgery. Bone and cartilage are more suitable because of the adequate rigidity and resistance to absorption. Synthetic materials have also been used, such as silicone balloons and silicone tubing. ${ }^{2,16)}$

We successfully treated two cases of empty sella syndrome, one of primary and the other of secondary origin, using silicone plates as the supporting material.

\section{Operative Technique}

Transsphenoidal extradural elevation of the sella, or chiasmapexy, was performed via the endonasal route under the guidance of a rigid 4-mm-diameter, 0-degree endoscope (Hopkins II; Karl Storz Endoskope, Tuttlingen, Germany). The patient was placed in the supine position and general anesthesia 

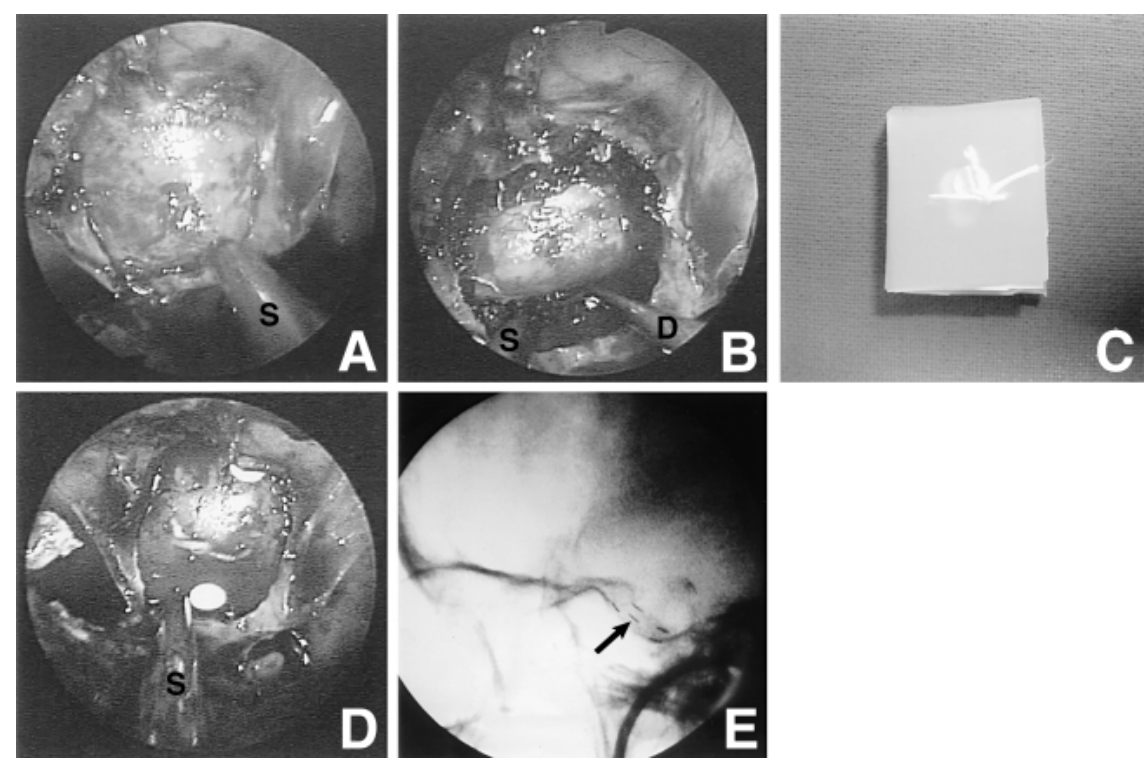

Fig. 1 Case 1. Intraoperative endoscopic views showing (A) the sellar floor with a $12 \times 12$ mm bone opening, (B) intrasellar extradural dissection with oxidized cellulose packed all around in the epidural space to achieve hemostasis and elevation at the same time, and (D) extradural elevation of the sellar contents accomplished by inserting two blocks of silicone plate into the sella turcica. S, suction; D, dissector. Photograph (C) showing a silicone block made of three pieces of silicone plate sutured in the center. Intraoperative fluoroscopic image (E) showing the position of the plates can be estimated by a small radiopaque mark on each plate (arrow). was induced. The overall approach to the sella turcica was the same as that of endonasal endoscopic pituitary surgery. ${ }^{1,9)}$ Briefly, the sphenoethmoidal recess was approached under endoscopic vision, where the natural ostium of the sphenoid sinus was identified. The septal mucosa was cauterized 1 or 2 $\mathrm{cm}$ anterior to the ostium and the anterior wall of the sphenoid sinus was exposed on the same side. The nasal septum was then fractured to the opposite side, and submucosal dissection was performed to expose the whole rostrum of the sphenoid sinus. The sphenoid sinus was opened as large as possible with a drill and a Kerrison punch. The bony septum in the sinus was removed to fully expose the sella turcica in the endoscopic view. The sellar floor was opened in a square shape, as in pituitary tumor surgery, with a drill and a bone punch (Fig. 1A). Care was taken in creating the window to not reveal the cavernous sinus dura laterally, but to encompass the entire sellar floor widthwise. The anteroposterior length was about the same size as the width, but should be located rather posteriorly toward the bottom. Epidural dissection was carried out by inserting pieces of oxidized cellulose (Surgicel; Johnson \& Johnson Wound Management Worldwide, Somerville, N.J., U.S.A.) all around between the dura and the bony sellar floor. This maneuver allowed simultaneous epidural dissection, hemostasis, and elevation of the dura (Fig. 1B). Two or three pieces of 1-mm-thick silicone plate (Koken, Tokyo), cut larg- er than the sellar window by $1 \mathrm{~mm}$ in width and $3 \mathrm{~mm}$ in length, were sutured at the center to make a silicone block (Fig. 1C). Each plate had a white radiopaque dot detectable by fluoroscopy. Two or three blocks were inserted beneath the dura into the epidural space, with the length placed in the anteroposterior direction (Fig. 1D). Insertion was not difficult, even though the block was larger than the window, because the silicone plate is elastic and pliable. The position of the block was adjusted by grasping the suture knot with forceps. The extent of elevation was planned preoperatively from the magnetic resonance (MR) images and estimated intraoperatively by fluoroscopy (Fig. 1E). After confirming that the blocks were securely positioned in the space, the nasal cavity was packed with gauze impregnated with antibiotic ointment.

\section{Case Reports}

Case 1: A 36-year-old woman presented with left visual disturbance after a long period of bromocriptine treatment for a prolactinoma. She had amenorrhea and galactorrhea at age 17 years. She refused surgery, and had been treated with bromocriptine under a diagnosis of prolactin-secreting macroadenoma. She began to notice a gradual decline of visual acuity on the left at age 34 years. On admission, MR imaging revealed herniation of the optic chiasm into the enlarged empty sella (Fig. 2A). 

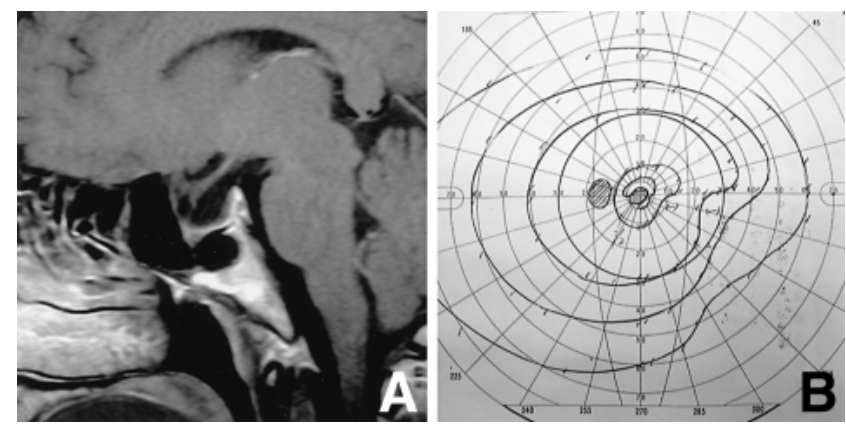

Fig. 2 Case 1. A: Preoperative sagittal $T_{1}$-weighted magnetic resonance image demonstrating the enlarged sella turcica and concave deformity of the chiasm tethered by what seems to be adhesion tissue. B: Goldman perimetry graph showing a central scotoma and right lower visual field defect in the left eye.

Visual field examination revealed a left central scotoma with bilateral right lower visual field defects (Fig. 2B). Visual acuity was 0.2 in the left eye, and funduscopy revealed mild optic atrophy on the same side. The diagnosis was secondary empty sella syndrome, and chiasmapexy was indicated to prevent further worsening of the vision.

The procedure was performed as described with a $12 \times 12 \mathrm{~mm}$ bone opening (Fig. 1). Two silicone blocks, one made of two and the other of three pieces of silicone plate, were used, resulting in at least 5-mm elevation. The nasal packing was removed the day after surgery. The patient reported some nasal discomfort and nasal obstruction, but no pain related to the procedure. Postoperative MR imaging showed adequate elevation of the sellar contents (Fig. 3A). The central scotoma and the visual field defect had improved slightly by day 7 after the operation (Fig. 3B). No remarkable improvement in the visual field was noticed during the follow-up period of 17 months, but visual acuity improved to 1.2 in the left eye.

Case 2: A 79-year-old man presented with blurred vision in the right eye and persistent headache. The symptoms had appeared 2 years before and gradually worsened. MR imaging showed the sella was enlarged and the pituitary stalk was elongated toward the sellar floor, without optic system herniation (Fig. 4A). Humphrey perimetry showed that the right central visual field was encroached upon by a scotoma from the right upper side (Fig. 4B). Only the empty sella was detected to explain the symptoms, so the patient consented to chiasmapexy.

The procedure was performed as described with an $11 \times 11 \mathrm{~mm}$ bone opening. Two silicone blocks,
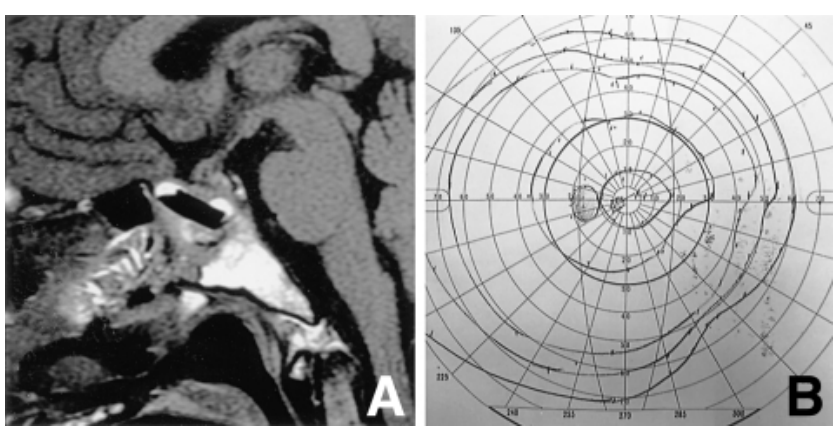

Fig. 3 Case 1. A: Postoperative sagittal $T_{1^{-}}$ weighted magnetic resonance image demonstrating adequate elevation of the sellar contents with the silicone plates, which appear as low intensity. B: Goldman perimetry graph showing some improvement in the central scotoma and the defect in the left visual field. No further deterioration was detected during the follow-up period.
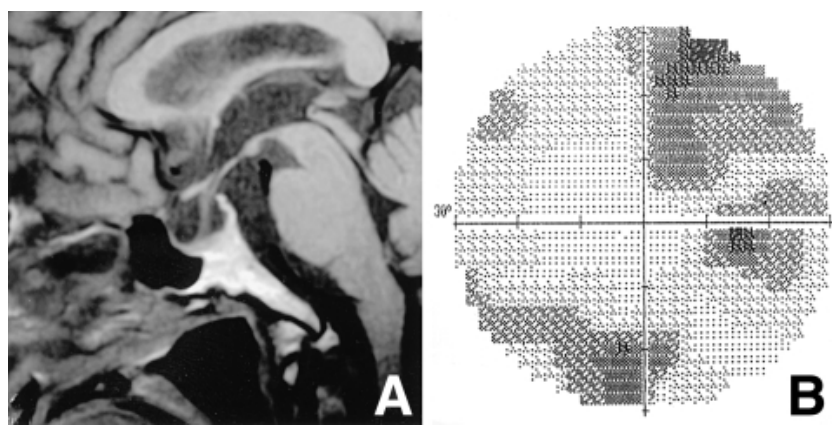

Fig. 4 Case 2. A: Preoperative sagittal $T_{1}$-weighted magnetic resonance image demonstrating the elongated pituitary stalk protruding into the enlarged empty sella, without optic system herniation. B: Humphrey perimetry graph showing a right upper scotoma near the central visual field in the right eye.

both made of two pieces of silicone plate, were inserted, resulting at least 4-mm elevation. The nasal packing was removed the day after surgery. Postoperative MR imaging showed adequate elevation of the sellar contents (Fig. 5A). Perimetry showed that the visual field had normalized 10 days after the operation (Fig. 5B). The persistent headache also subsided. The patient was symptomfree at the follow-up examination 13 months later.

\section{Discussion}

The present technique for chiasmapexy used silicone blocks made of two or more pieces of silicone 

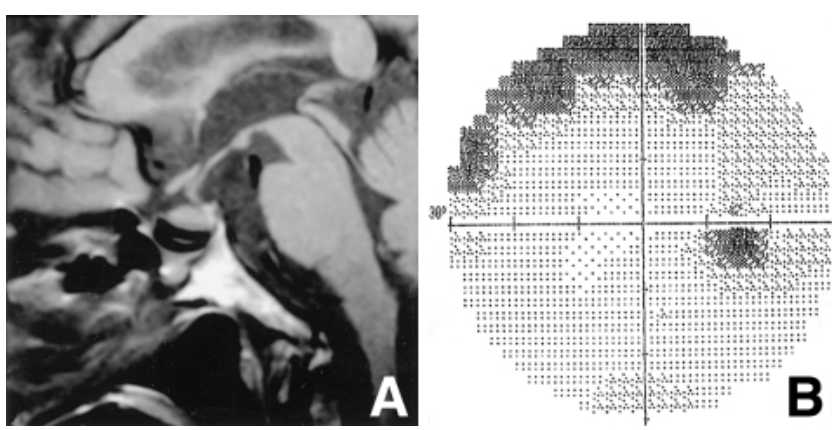

Fig. 5 Case 2. A: Postoperative sagittal $\mathbf{T}_{\mathbf{1}^{-}}$ weighted magnetic resonance image demonstrating good elevation of the sellar contents. B: Humphrey perimetry graph showing disappearance of the right upper scotoma in the right visual field.

plate sutured at the center. This method has several advantages. Silicone is a biocompatible material and is widely used in the living body for prostheses, so the safety has been documented. ${ }^{11,12,16)}$ Silicone is not absorbable like fat or muscle, so there is little risk of re-descent of the sella and subsequent recurrence of the symptoms. ${ }^{16)}$ Silicone plate is easy to shape by cutting with scissors during the operation, so can be fitted into a bony opening of any shape. ${ }^{12,13)}$ Silicone plate is elastic, so is easy to insert, even if larger than the bone window. ${ }^{12)}$ Silicone plate is rigid enough to support the sella. ${ }^{11-13)}$ Changing the number of plates to be inserted can control the extent of elevation. Making a block with the plates by suturing in the center allows an elevation of 4 to $6 \mathrm{~mm}$ with only two insertions, which is generally adequate for the purpose. If the plates were handled as separate pieces, the procedure would have to be repeated several times to achieve adequate elevation. Repeated procedures carry the risk that one or more plates could slip out of place during the following insertion. However, a thick block made of five or six plates would be rather cumbersome to place and position in a narrow space such as the sphenoid sinus and sella turcica. The suture knot can be grasped with forceps, so the block is very easy to handle and to adjust once positioned in the sella. Removal of the plate at a second surgery should be easy because silicone does not adhere strongly to the surrounding tissue. ${ }^{11)}$ After cutting the suture at the center, the plates can be removed one by one until the ideal height is reached.

After opening the sellar floor and before inserting the silicone block, extradural dissection between the dura and the sellar bone is necessary. The epidural space all around was packed with pieces of oxidized cellulose. Hemostasis was easily achieved even in this location, where bleeding is likely to occur because of the proximity of the cavernous sinus and the intercavernous sinus. This procedure achieved hemostasis at the same time as dissection and dural elevation.

We used the endonasal endoscopic approach in both our patients, although we could have used the conventional sublabial transsphenoidal approach. ${ }^{7}$ ) The sella and the surrounding critical structures such as the carotid prominence could be clearly seen in the panoramic view of the endoscope, decreasing the risk of injury to these vital structures.9) The occasional gingival swelling and numbness that follows the conventional sublabial approach was completely avoided. ${ }^{9)}$ The patients returned to daily activities within days of the operation because the endonasal endoscopic approach involves less pain and discomfort than the conventional approach. ${ }^{1,9)}$ We suggest that the endonasal endoscopic approach could be used to treat skull base lesions other than empty sella syndrome. ${ }^{4)}$

\section{References}

1) Cappabianca P, Cavallo LM, Colao A, Del Basso De Caro M, Esposito F, Cirillo S, Lombardi G, de Divitiis E: Endoscopic endonasal transsphenoidal approach: outcome analysis of 100 consecutive procedures. Minim Invasive Neurosurg 45: 193-200, 2002

2) Cybulski GR, Stone JL, Geremia G, Anson J: Intrasellar balloon inflation for treatment of symptomatic empty sella syndrome. Neurosurgery 24: 105-109, 1989

3) Czech T, Wolfsberger S, Reitner A, Gorzer $\mathrm{H}$ : Delayed visual deterioration after surgery for pituitary adenoma. Acta Neurochir (Wien) 141: 45-51, 1999

4) de Divitiis E, Cappabianca P, Cavallo LM: Endoscopic transsphenoidal approach: adaptability of the procedure to different sellar lesions. Neurosurgery 51: 699-707, 2002

5) Gallardo E, Schachter D, Caceres E, Becker P, Colin E, Martinez C, Henriquez C: The empty sella: results of treatment in 76 successive cases and high frequency of endocrine and neurological disturbances. Clin Endocrinol (Oxf) 37: 529-533, 1992

6) Garcia-Uria J, Ley L, Parajon A, Bravo G: Spontaneous cerebrospinal fluid fistulae associated with empty sellae: surgical treatment and long-term results. Neurosurgery 45: 766-774, 1999

7) Guinto G, del Valle R, Nishimura E, Mercado M, Nettel B, Salazar F: Primary empty sella syndrome: the role of visual system herniation. Surg Neurol 58: 42-48, 2002

8) Hamlyn PJ, Baer R, Afshar F: Transsphenoidal chiasmapexy for long standing visual failure in the secondary empty sella syndrome. Br J Neurosurg 2: 277-279, 1988 
9) Jho HD: Endoscopic transsphenoidal surgery, in Schmidek HH (ed): Schmidek \& Sweet Operative Neurosurgical Techniques: Indications, Methods, and Results. Philadelphia, WB Saunders, 2000, pp 385-397

10) Jones SE, James RA, Hall K, Kendall-Taylor P: Optic chiasmal herniation - an under recognized complication of dopamine agonist therapy for macroprolactinoma. Clin Endocrinol (Oxf) 53: 529-534, 2000

11) Kabuto M, Kubota T, Kobayashi H, Takeuchi H, Nakagawa T, Kitai R, Kodera T, Kawai H, Arishima $\mathrm{H}$ : Long-term evaluation of reconstruction of the sellar floor with a silicone plate in transsphenoidal surgery. J Neurosurg 88: 949-953, 1998

12) Kim J, Cheong J, Yi H, Bak K, Kim C, Lee S: Usefulness of silicone plate for sellar floor reconstruction. Minim Invasive Neurosurg 45: 124-127, 2002

13) Kubo S, Hasegawa H, Inui $T$, Tominaga S, Yoshimine $\mathrm{T}$ : [Endonasal endoscopic repair of a traumatic encephalocele and cerebrospinal fluid rhinorrhea: case report]. No Shinkei Geka Sokuho 14: 1019-1025, 2004 (Jpn, with Eng abstract)

14) Olson DR, Guiot G, Derome P: The symptomatic empty sella. Prevention and correction via the transsphenoidal approach. J Neurosurg 37: 533-537, 1972

15) Spaziante R, de Divitiis E, Cappabianca P: Repair of the sella turcica after transsphenoidal surgery, in Schmidek HH (ed): Schmidek \& Sweet Operative Neurosurgical Techniques: Indications, Methods, and Results. Philadelphia, WB Saunders, 2000, pp 406-408

16) Zona G, Testa V, Sbaffi PF, Spaziante R: Transsphenoidal treatment of empty sella by means of a silastic coil: technical note. Neurosurgery 51: 1299-1303, 2002

Address reprint requests to: S. Kubo, M.D., Endoscopic Neurosurgery Center, Tominaga Hospital, 1-4-48 Minato-machi, Naniwa-ku, Osaka 556-0017, Japan. e-mail: sig-kubo@momo.so-net.ne.jp

\section{Commentary}

The authors present two cases of chiasmapexy for progressive visual loss associated with an empty sella. They use the endoscopic transnasal transsphenoidal technique for the approach and silicone plates put together to form blocks to bolster the dura in the sella. There was at least some visual improvement in both cases.

The indications for chiasmapexy are difficult but we have tended to favor recommending the procedure when there has been progressive loss associated with a primary or more likely a secondary empty sella. Our approach has usually been one of performing an extra dural dissection within the sella after appropriate removal of the sellar floor. The material used to pack the sella ordinarily has been fat tissue or muscle and both of these have worked well as autologous grafts. The idea to use silicone, balloon or other materials has been published from time to time and it certainly appears that these constructs achieve the same end of elevating the optic chiasm and in many cases restoring vision.

\section{Edward R. Laws, Jr., M.D., F.A.C.S. Department of Neurosurgery University of Virginia Charlottesville, Virginia, U.S.A.}

The authors have reported two cases of empty sellar syndrome treated by endoscopic transsphenoidal operation. Transsphenoidal chiasmapexy is indicated in the rare instance when the optic chiasm herniated inside the sella and causes progressive visual disturbance. The authors used insertion of extradural silicone plates into the sellar space. This technique allows the sellar space to be obliterated by silicone plates in order to decrease the stretching of visual pathways and their vascular supply. The advantage of this operation is the extradural approach. There is no need to open the sellar dura, and operation associated with endonasal endoscopy is a minimally invasive and safe operation. Visual symptoms improved in both patients after operation. I believe this technique is reasonable to treat the symptomatic empty sella.

Shu-yuan YANG, M.D. Department of Neurosurgery Tianjin Medical University General Hospital Tianjin, P.R.C. 